\title{
Monoamine metabolites in cerebrospinal fluid in multiple sclerosis
}

\author{
D. DA V I D O N, ${ }^{1}$ I. A. P ULLAR, ${ }^{2}$ C. MA W D LEY, \\ NA NCY K I N L O C H, A N D CELIA M. YATES
}

From the MRC Brain Metabolism Unit, Department of Pharmacology, and Department of Medical Neurology, University of Edinburgh, Edinburgh, Scotland

SUMMARY The concentrations of homovanillic acid (HVA), 5-hydroxyindolylacetic acid (5HIAA), and 4-hydroxy, 3-methoxyphenylethylene glycol (MHPG) were estimated in the lumbar cerebrospinal fluid (CSF) of control subjects and in some patients who probably, and others who definitely, suffered from multiple sclerosis (MS). In the control group, the concentration of HVA was lower in people who underwent lumbar puncture having fasted and been recumbent for 12 hours before the procedure than in those from whom CSF was obtained under nonstandardised conditions. These studies demonstrate that a standardised procedure for lumbar puncture is required in order to obtain meaningful results. In patients suffering from MS the CSF 5-HIAA concentrations were significantly lower than in comparable controls but the HVA concentrations did not differ. There was no relationship between metabolite concentrations, site of lesion, the duration of the disease, $\gamma$-globulin levels nor the occurrence of relapse within the previous month.

The concentrations of monoamine metabolites have been estimated in lumbar CSF in a variety of neurological disorders. They serve as indirect indices of the turnover of the parent amines in the central nervous system (Garelis et al., 1974). The acid metabolites, homovanillic acid (HVA), and 5-hydroxyindolylacetic acid (5-HIAA), are derived from dopamine and 5-hydroxytryptamine (5HT) respectively; the alcohol metabolite 4hydroxy, 3-methoxyphenylethylene glycol (MHPG) is formed from noradrenaline. In recent CSF studies in multiple sclerosis (MS) raised concentrations of HVA in patients suffering acute exacerbations (Sonninen et al., 1973) and low concentrations of both HVA and 5-HIAA in severely affected, immobile patients (Claveria et al., 1974; Johansson and Roos, 1974) have been reported, suggesting that synaptic mechanisms are altered in MS. However, the conditions of CSF sampling, which may influence the metabolite

\footnotetext{
'Present address: Department of Neurology, PO Box 72, Royal Infirmary, Dundee, DD1 9ND, Scotland.

${ }^{2}$ Present address: Lilly Research Centre Ltd, Erl Wood Manor, Windlesham, Surrey, England.

Address for reprint requests: Celia M. Yates, Department of Pharmacology, 1 George Square, Edinburgh, EH8 9JZ, Scotland.

Accepted 22 February 1977
}

concentrations in the CSF, were not described. We have, therefore, assessed the effect of a standardised lumbar puncture technique by estimating HVA, 5-HIAA, and MHPG levels with and without standardisation of motor activity, food intake, and time of puncture. Cerebrospinal fluid was obtained from patients who were suffering from multiple sclerosis ('definite' group) and from those who 'probably' had multiple sclerosis. These patients were categorised according to the criteria of McAlpine et al. (1972). The concentrations of the metabolites in the cerebrospinal fluid were measured and an attempt made to correlate these levels with various clinical features.

\section{Methods}

PATIENTS AND TECHNIQUE OF LUMBAR PUNCTURE Controls

There were two control groups. The first was a group of 18 patients (12 males and six females) with tension headache, migraine, or functional disorders in whom lumbar puncture was performed as part of their neurological investigation. Lumbar puncture was performed in the lateral decubitus position at midday, after the patients had fasted and been recumbent for 12 hours. The 
first $5 \mathrm{ml}$ of CSF, taken for metabolite estimation, were immediately frozen and stored thus until the assay could be performed. Only $5 \mathrm{ml}$ of CSF were used since removal of a greater volume might cause varying results because of contamination of the specimen by CSF from higher levels. The second control group of 20 patients had CSF removed at myelography for the investigation of possible lumbar or cervical spondylosis. Physical activity before puncture, time of puncture, and diet in this latter group, were not controlled. The CSF was treated in exactly the same way as in the first group. In neither group was air injected before CSF was removed. In both groups, patients receiving phenothiazines, antihypertensive drugs, salicylates, antidepressants, and barbiturates were excluded. Some patients received nitrazepam the night before lumbar puncture.

\section{Multiple sclerosis patients}

Sixteen patients (five males and 11 females) with 'probable' and 31 patients (15 males and 16 females) with 'definite' MS underwent the standardised procedure for lumbar puncture. The interval since the patient's last relapse, the site of his or her lesions, duration of the disease, and the concentration of $\gamma$-globulin in the CSF were recorded.

BIOCHEMICAL ESTIMATIONS

The HVA and 5-HIAA were measured essentially by the method of Pullar et al. (1970) and MHPG essentially by the method of Sharman (1969) as modified by Walter (1973).

\section{Estimation of $H V A$ and 5-HIAA}

Fifty microlitres of ascorbic acid $2 \mathrm{mg} / \mathrm{ml}$ were added to $4 \mathrm{ml} \mathrm{CSF}$. The sample was acidified with $100 \mu 12 \mathrm{~N} \mathrm{HCl}$ saturated with $\mathrm{NaCl}$, and the phenolic acids removed into distilled butyl acetate (BDH Reagent grade) by twice shaking the sample for five minutes with $10 \mathrm{ml}$ of the solvent. The butyl acetate extracts were combined after separation from the aqueous phase by centrifugation at $2000 \mathrm{~g}$ for five minutes. The phenolic acids in the pooled butyl acetate extracts were removed into $1.4 \mathrm{ml}$ of $0.1 \mathrm{M}$ borate buffer ( $\mathrm{pH} 8.6$ ) by shaking for five minutes followed by centrifugation to separate the phases. Two $0.5 \mathrm{ml}$ portions of the aqueous phase were estimated for HVA and 5-HIAA, respectively.

$H V A$ To a $0.5 \mathrm{ml}$ sample was added $200 \mu 1$ of a freshly prepared mixture of $12.2 \mathrm{ml}$ concentrated ammonia, $12.8 \mathrm{ml}$ water, and $100 \mu \mathrm{l}$ $\mathrm{K}_{3} \mathrm{Fe}(\mathrm{CN}) 611 \mathrm{mg} / \mathrm{ml}$. After exactly four minutes, oxidation was stopped by the addition of
$50 \mu \mathrm{l}$ cysteine $1.75 \mathrm{mg} / \mathrm{ml}$. The fluorescence was read on a Perkin-Elmer spectrophoto-fluorimeter at an excitation wavelength of $320 \mathrm{~nm}$ and an emission wavelength of $418 \mathrm{~nm}$.

5-HIAA To a $0.5 \mathrm{ml}$ sample was added $200 \mu \mathrm{l}$ concentrated $\mathrm{HCl}$ containing ascorbic acid $1 \mathrm{mg} /$ $\mathrm{ml}$. The fluorescence was immediately measured at an excitation wavelength of $310 \mathrm{~nm}$ and an emission wavelength of $535 \mathrm{~nm}$, with a filter which prevented transmission of wavelengths greater than $390 \mathrm{~nm}$, inserted into the emission beam.

Standard amounts of HVA and 5-HIAA (20$200 \mathrm{ng}$ ) in $4 \mathrm{ml}$ water were processed in parallel with each batch of CSF samples.

\section{Estimation of MHPG}

One millilitre of CSF was made up to $2.0 \mathrm{ml}$ with water and $100 \mu \mathrm{l} 1 \mathrm{M}$ sodium acetate buffer, pH 5.0 and $50 \mu 1$ Helicase $50 \mathrm{mg} / \mathrm{ml}$, and added. Helicase (Micro-Bio Labs. Ltd) was purified by acetone precipitation before use. The sample was incubated overnight at $37^{\circ} \mathrm{C}$ to hydrolyse MHPG sulphate. The free glycol was extracted into ethyl acetate (Reeve Angel Scientific CT grade) by shaking twice, respectively with $4 \mathrm{ml}$ and $3 \mathrm{ml}$ of ethyl acetate for five minutes. The phases were separated by centrifugation and the ethyl acetate layers combined and evaporated to dryness under $\delta$ nitrogen at $56^{\circ} \mathrm{C}$. The residue was taken up in $0.4 \mathrm{ml}$ water and acetylated by the addition of $50 \mu \mathrm{l}$ distilled acetic anhydride and $1.6 \mathrm{ml} \mathrm{KHCO}_{3}$ $0.165 \mathrm{~g} / \mathrm{ml}$. After 30 minutes $1.6 \mathrm{ml}$ dichloromethane (BDH redistilled) was added and the sample agitated for one minute on a vortex mixer and centrifuged to separate the phases. A $1.3 \mathrm{ml}$ sample of the organic phase, which contained the acetylated derivative of the glycol, was dried over anhydrous $\mathrm{Na}_{2} \mathrm{SO}_{4}$ and then evaporated to dryness under nitrogen at $56^{\circ} \mathrm{C}$. The residue was taken up in $0.6 \mathrm{ml}$ trifluoroacetic anhydride mixture (one part trifluoroacetic anhydride (Sigma) + five parts ethyl acetate) and the test tubes stoppered and heated for 15 minutes at $56^{\circ} \mathrm{C}$ to convert acetylated MHPG into its fluorinated derivative. The sample was then evaporated carefully to dryness under nitrogen at $56^{\circ} \mathrm{C}$. The residue was taken up in $200 \mu \mathrm{l}$ ethyl acetate containing $\gamma$-benzene hexachloride $15 \mathrm{ng} / \mathrm{ml}$ as internal standard, and $4 \mu 1$ of this solution was injected into the chromatogram. Standard amounts of MHPG (10-50 ng) in $2.0 \mathrm{ml}$ water were processed in parallel with each batch of CSF samples. Bis (4-hydroxy-3methoxy-phenylglycol) piperazine salt was purchased from Sigma.

A Perkin-Elmer model 900 gas-liquid chroma- 
togram with a ${ }^{63} \mathrm{Ni}$ electron capture detector was used. The column was two metres long, $4.6 \mathrm{~mm}$ internal diameter, stationary phase $2.5 \%$ silicone gum rubber E 301 on a support of chromosorb G AW DMCS 80-100 mesh. The carrier gas was argon containing $10 \%$ methane used at a flow rate of $60 \mathrm{ml} / \mathrm{min}$. The column temperature was $170^{\circ} \mathrm{C}$. The amount of MHPG in each sample was calculated from the peak heights by the ratio method (Sharman, 1969).

\section{Results}

There was no significant difference between the ages of the control groups of patients (Tables 1 and 2).

The CSF concentrations of HVA, 5-HIAA, and MHPG in the four groups of patients and controls are shown in Table 1. The concentration of HVA in control group 2, in which the conditions before lumbar puncture were not standardised, was greater than in control group $1(\mathrm{P}<0.01)$, in which the conditions before puncture were standardised. There was no difference between the concentrations of 5-HIAA and MHPG in the standardised and in the non-standardised control groups. The 5-HIAA concentrations in the definite MS group was $12 \pm 6 \mathrm{ng} / \mathrm{ml}(\mathrm{n}=31)$, which was significantly lower than the 5-HIAA concentration of $19 \pm 8 \mathrm{ng} / \mathrm{ml}(\mathrm{n}=18)$ in control group $1(\mathrm{P}<0.005)$. The probable $\mathrm{MS}$ group had an intermediate level of $15 \pm 9 \mathrm{ng} / \mathrm{ml}(\mathrm{n}=16)$. In the definite MS group, the 5-HIAA concentration in patients with severe motor impairment did not differ from patients with minimal loss of mobility. The concentrations of HVA and MHPG in the probable and definite MS groups did not differ significantly from the concentrations in control group 1.

In the definite MS group there were no differences in the metabolite concentrations in CSF obtained from patients with involvement of the spinal cord; nor was there any significant difference between those with primary sensory manifestations and those with severe pyramidal tract disorders. There were no differences between those patients who had sustained a relapse within the month before lumbar puncture and those who had not manifested a recent relapse (Table 2). The metabolite concentrations did not correlate with the $\gamma$-globulin concentrations.

\section{Discussion}

Patients in whom CSF was removed under nonstandardised conditions had higher concentrations of HVA in their CSF than did those in whom a standardised lumbar puncture technique was used. Motor activity before lumbar puncture as well as individual variations might account for the higher

Table $1 H V A, 5-H I A A$, and MHPG concentrations in lumbar CSF from control patients and patients with multiple sclerosis

\begin{tabular}{|c|c|c|c|c|}
\hline \multirow[t]{2}{*}{ Group } & Age (yr) & $H V A(n g / m l)$ & 5-HIAA (ng/ml) & $M H P G(n g / m l)$ \\
\hline & \multicolumn{4}{|c|}{$M e a n \pm S D(n)$} \\
\hline $\begin{array}{l}\text { Control } 1 \text { : fasted and recumbent for } 12 \mathrm{~h} \text { before LP } \\
\text { Control } 2 \text { : conditions before LP not controlled } \\
\text { Probable MS: fasted and recumbent for } 12 \mathrm{~h} \text { before LP } \\
\text { Definite MS: fasted and recumbent for } 12 \mathrm{~h} \text { before LP }\end{array}$ & $\begin{array}{l}41 \pm 15(18) \\
43 \pm 15(20) \\
41 \pm 15(16) \\
41 \pm 12(31)\end{array}$ & $\begin{array}{l}29 \pm 13(17) \\
48 \pm 23(20)^{*} \\
27 \pm 13(11) \\
32 \pm 15(31)\end{array}$ & $\begin{array}{l}19 \pm 8(18) \\
18 \pm 8(19) \\
15 \pm 9(16) \\
12 \pm 6(31) \dagger\end{array}$ & $\begin{array}{l}10 \pm 5(11) \\
10 \pm 5(12) \\
13 \pm 4(9) \\
10 \pm 4(23)\end{array}$ \\
\hline
\end{tabular}

*HVA in control group 2 greater than in other groups $(\mathrm{P}<0.01)$.

†5-HIAA in definite MS less than in control group $1(\mathrm{P}<0.005)$.

LP=lumbar puncture.

Table $2 H V A, 5-H I A A$, and MHPG concentrations in lumbar CSF in relation to clinical features of patients with multiple sclerosis (patients fasted and recumbent for $12 \mathrm{~h}$ before LP)

\begin{tabular}{|c|c|c|c|c|}
\hline \multirow[t]{2}{*}{ Clinical feature } & Age $(y r)$ & $H V A(n g / m l)$ & 5-HIAA (ng/ml) & $M H P G(n g / m l)$ \\
\hline & \multicolumn{4}{|c|}{$M e a n \pm S D(n)$} \\
\hline $\begin{array}{l}\text { Myelopathy, paraesthesiae } \\
\text { Myelopathy, motor deficit } \\
\text { Indication of brainstem involvement } \\
\text { No indication of brainstem involvement } \\
\text { Relapse within month before LP } \\
\text { No relapse within month before LP }\end{array}$ & $\begin{array}{l}43 \pm 7(7) \\
44 \pm 14(16) \\
39 \pm 12(13) \\
42 \pm 12(18) \\
40 \pm 8(11) \\
41 \pm 14(20)\end{array}$ & $\begin{array}{l}29 \pm 15(7) \\
33 \pm 17(16) \\
35 \pm 12(13) \\
30 \pm 16(18) \\
32 \pm 14(11) \\
31 \pm 17(20)\end{array}$ & $\begin{array}{l}13 \pm 7(7) \\
11 \pm 5(16) \\
14 \pm 6(13) \\
10 \pm 5(18) \\
14 \pm 6(11) \\
11 \pm 5(20)\end{array}$ & $\begin{array}{l}11 \pm 4(6) \\
10 \pm 5(11) \\
11 \pm 4(9) \\
10 \pm 4(14) \\
11 \pm 3(7) \\
10 \pm 5(16)\end{array}$ \\
\hline
\end{tabular}


HVA concentrations in CSF from the former group. Exercise increases the levels of HVA and 5-HIAA in lumbar CSF (Post et al., 1973), probably because it results in an admixture of the cisternal CSF (which contains higher concentrations of these acids, Sjöstrom et al., 1975) with lumbar CSF. Since exercise has a more marked effect on the concentration of HVA than on that of 5-HIAA (Post et al., 1973), it is likely that relatively minor degrees of activity would cause an increase in HVA alone. The lack of any significant difference in the MHPG levels in CSF, taken by the different sampling techniques, is compatible with the similar concentrations of this metabolite in cisternal and in lumbar CSF (O'Keefe and Brooksbank, 1973; Sjöstrom et al., 1975). Diet and diurnal variation may also affect the concentrations of the amine metabolites in CSF. Our results are of interest because in previous studies on amine metabolites in CSF in MS, the conditions under which lumbar puncture was performed in the control group were either not described (Claveria et al., 1974; Johansson and Roos, 1974), or patients were 'kept in bed before lumbar puncture' for an unspecified period (Sonninen et al., 1973).

The significantly lower 5-HIAA concentration in lumbar CSF from patients with MS is unlikely to be due entirely to reduced mobility because the most immobile patients did not have the lowest 5-HIAA levels. The reduction in 5-HIAA may reflect a decrease in the spinal production of 5HIAA from 5HT-containing bulbospinal neurones since about $40 \%$ of the 5-HIAA in lumbar CSF originates from the spinal cord (Garelis et al., 1974). However, no difference was found between the concentrations of 5-HIAA in lumbar CSF from a group of patients who had only paraesthetic symptoms from those with marked motor disability from spinal cord lesions. Claveria et al. (1974) reported lower 5-HIAA concentrations in patients with cerebellar peduncular tremor but we found no difference between patients with and without brainstem involvement. The MHPG concentrations were not altered in MS.

Sonninen et al. (1973) postulated that an immunopharmacological block of receptors was responsible for the increase in amine metabolite values in acute lesions and for the decrease in the chronic stage which they observed in patients suffering from MS. The present results do not support this hypothesis since the concentrations of HVA and 5-HIAA were not elevated in the acute phase-that is, in patients who had had a relapse during the month before lumbar puncture-and there was no correlation of metabolite values with $\gamma$-globulin concentrations. An alternative possibility is that demyelination decreases neurotransmitter turnover. Reduction of 5-HT turnover with a consequent fall in the concentration of 5-HIAA in lumbar CSF could be related to the presence of demyelinating lesions along the bulbospinal tracts, which contain 5-HT fibres. Dopamine turnover would be less likely to be affected by demyelination because the nigrostriatal DA fibres are found in areas which have a low incidence of plaques. The relationship of demyelination to transmitter turnover requires further study because it is possible that clinical problems arising from deficient neurotransmitter activity could be modified by drug treatment despite the persistence of an established plaque.

We wish to thank Dr Ashcroft and Dr Crawford for discussion and advice, and Mrs Helen Wilson and Miss Eileen Walker for careful technical assistance.

\section{References}

Claveria, L. E., Curzon, G., Harrison, M. J. G., and Kantamaneni, B. D. (1974). Amine metabolites in cerebrospinal fluid of patients with disseminated sclerosis. Journal of Neurology, Neurosurgery, and Psychiatry, 37, 715-718.

Garelis, E., Young, S. N., Lal, S., and Sourkes, T. L. (1974). Monoamine metabolites in lumbar CSF: the question of their origin in relation to clinical studies. Brain Research, 79, 1-8.

Johansson, B., and Roos, B-E. (1974), 5-Hydroxy- 0 indolylacetic acid and homovanillic acid in CSF of patients with neurological disease. European Neurology, 11, 37-45.

McAlpine, D., Lumsden, C. E., and Acheson, E. D. (1972). In Multiple Sclerosis. A reappraisal. p. 202. Churchill Livingstone: Edinburgh and London.

O'Keefe, R., and Brooksbank, B. W. L. (1973). Determination of 3-methoxy-4-hydroxyphenylethylene glycol, a noradrenaline metabolite, in cercbrospinal fluid and urine. Clinical Chemistry, 19, 10311035.

Post, R. M., Kotin, J., Goodwin, F. K., and Gordon, E. K. (1973). Psychomotor activity and cerebrospinal fluid amine metabolites in affective illness. American Journal of Psychiatry, 130, 67-72.

Pullar, I. A., Weddell, J. M., Ahmed, R., and Gillingham, F. J. (1970). Phenolic acid concentration in the lumbar cerebrospinal fluid of Parkinsonian patients treated with L-dopa. Journal of Neurology, Neurosurgery, and Psychiatry, 33, 851-857.

Sharman, D. F. (1969). Glycol metabolites of noradrenaline in brain tissue. British Journal of Pharmacology, 36, 523-534.

Sjöstrom, R., Ekstedt, J., and Anggard, E. (1975). Concentration gradients of monoamine metabolites in human CSF. Journal of Neurology, Neurosurgery, and Psychiatry, 38, 666-668. 
Sonninen, V., Riekkinen, P., and Rinne, U.K. (1973). Walter, D. S. (1973). A study of the biochemical Acid monoamine metabolites in cerebrospinal fluid in multiple sclerosis. Neurology (Minneapolis), 23, 760-763. changes induced in a noradrenergic system in brain by electrical stimulation and lesions of this system. PhD Thesis, University of Edinburgh. 